\title{
Resultative constructions in Uyghur as verbal adjunction
}

\author{
Ahmatjan Tash \\ andrewtesol@xjufe.edu.cn \\ Alexander Sugar \\ University of Washington \\ sugara@u.washington.edu
}

Xinjiang University of Finance and Economics

\begin{abstract}
This paper analyzes resultative constructions in Uyghur as an adjunction relationship between two verbal projections. Uyghur resultatives differ from previously analyzed resultatives, including those in typologically related Altaic languages (see Shibagaki 2011), in that both predicates must match share a subject. One verb encodes a resultative meaning while the other elaborates the manner of achieving the result state, but the ordering is flexible. The only ordering requirement is that the final verb and the object form a telic verb constellation. The unique structure of this construction points to the conclusion that the notion of 'resultative construction' does not correspond to any specific syntactic structure crosslinguistically.
\end{abstract}

Keywords: resultative constructions; Uyghur; syntax; adjunction; multi-verb constructions

\section{Introduction}

A wide variety of languages across the world employ a strategy for expressing that a given action leads to a certain change of state. When this strategy involves relating two juxtaposed predicates interpreted as describing a single event - one predicate describing an action and the other a resulting state that holds upon the action's termination or culmination - it has been termed a resultative construction (RVC) (Halliday 1967; Rothstein 2006; Lee 2013 and many others). However, a cross-linguistically uniform definition or description of an RVC has not been established because it can take many forms (Thepkanjana \& Uehara 2009), and lack of uniformity even in a single language led Goldberg \& Jackendoff (2004) to term the RVC a "family of constructions' rather than a definable construction in itself.

RVCs in the Altaic language Uyghur, spoken mainly in Western China, take the form of Subj $+\mathrm{Obj}+\mathrm{V} 1-(\mathrm{i}) \mathrm{p}$ (non-finite) $+\mathrm{V} 2$-(wet) (finite), where $\mathrm{V} 1$ is a non-final verb and V2 is a sentence-final verb that imme- 
diately follows V1. ${ }^{1}$ The V1-(i)p (non-finite) + V2 (finite) structure is in fact the form used for a variety of multi-verb constructions in the language, as will be discussed in section 2 . The significance of the -(i) $p$ suffix and the optionality of the -wet suffix will be discussed shortly. While V1 must always be non-finite (lacking tense or person agreement morphology) and V2 finite, there is some flexibility as to whether V1 or V2 describes an action encoding a result versus an action that leads to a result.

In (1), V2 tüzle 'to flatten' describes an action that entails a certain result if it is completed: the object, in this case mital 'metal', becoming flat. V1 ur 'to hit' seems to describe the manner in which the flattening action is performed.

(1) Ahmat mitalni urup tüzliwetti

Ahmat mital-ni ur-(i)p tüzle-wet-di-0

(name) metal-AC hit-LINK flatten-COMP-PST-3

'Ahmat hit the metal flat.'

In (2), the opposite relationship is formed between the two verbs. V1 qizil qil 'to redden' is a causative compound verb entailing a resulting state: the object tam 'wall' becoming red. V2 boy 'to paint' describes a manner of making the wall red.

(2) Ahmat tamni qizil qilip boyiwetti

Ahmat tam-ni qizil qil-(i)p boy-wet-di-0

(name) wall-ACC red do-LINK paint-COMPL-PST-3

'Ahmat painted the wall red.'

The purpose of this paper is to introduce the form of RVCs in Uyghur, explain the relationship of their component parts, and analyze their underlying structure. First, we describe in section 2 the necessary role of the -(i)p suffix in linking two verbs (section 2) and the optional but preferred presence of the -wet suffix to emphasize a complete change of state (section 3 ). Then, in section 4, we explain that the linear order between V1 and V2 is flexible as long as the aspectual constellation formed by the sentential object and V2 is telic. In section 5, we show that Uyghur RVCs display the traditional RVC behavior of monoclausality. In section 6 , we argue that $\mathrm{V} 1$ is adjoined to V2, as opposed to being a complement of V2. Section 7 shows that V2 is structurally superior to V1 and sketches a possible structure for two varieties of RVCs. Section 8 summarizes some key differences

${ }^{1}$ We write the verb-linking suffix as -(i)p to show that the vowel is subject to harmonic variation. 
between Uyghur RVCs and RVCs in typologically similar languages, and section 9 concludes the paper.

\section{Linking verbs using the -(i)p suffix}

Uyghur resultative constructions take the form of $-(i) p$ constructions. By -(i) $p$ construction we mean any sentence in which only the final verb is inflected for tense and person, and all non-final verbs end in -(i) $p$. - (i) $p$ constructions bear a surface resemblance to serial verb constructions (SVCs), although the presence of the -(i)p marker itself may mean that the construction does not fit the strictest definitions of SVCs (Aikhenvald \& Dixon 2014). Since Larson (1991), Cormack \& Smith (1994), Cormack \& Smith (1999), and Collins (1997), there has been an effort in syntactic literature to connect the structure of SVCs to those of RVCs. It is unclear how well the data presented here sustains that connection, since -(i)p constructions differ from cannonical SVCs - and Uyghur RVCs from RVCs in other languages - in significant ways, and since there is reason to believe that the structure of different subtypes of $-(i) p$ constructions is not uniform (Sugar 2017).

Perhaps the most common use of $-(i) p$ is in a string of phrases each ending in a lexical verb. -(i) $p$ attaches to every non-final verb in such a construction, and the reading can be that the event denoted by each verb happened either sequentially or simultaneously. ${ }^{2}$

(3) Biz uning öyide yep, ichip,

Biz u-ning öy-i-da ye-(i)p ich-(i)p

1PL 3SG-GEN home-3.POSS-LOC eat-LINK drink-LINK

parangliship, ussul oyniduq.

paranglash-(i)p ussul oyna-di-uq

chat-LINK dance play-PST-1SG

Sequential reading: 'After we had eaten in his house, (then) we drank and talked, and after that we danced.'

Simultaneous reading: 'We were eating, drinking, talking and dancing in his home.'

(Engesæth et al. 2009: 221)

${ }^{2}$ Ussul oyna 'dance play' is a compound verb rather than a multi-verbal construction. Ussul is treated as a noun throughout Uyghur grammar, and cannot take verbal inflection. Verbalizing a non-verbal item, usually of foreign origin, by placing it adjacent to a native verb is a productive strategy in Uyghur grammar (Memtimin 2016). Nicholas Kontovas states in a personal communication that ussul comes from an Arabic word meaning "origins'. 
Another type of $-(i) p$ construction has been identified in which the final, finite verb is drawn from a limited class and contributes aspectual or agentive information rather than a lexical meaning to the sentence (Ibrahim 1995; Tömür 2003). In (4), for example, the final verb qal no longer has the lexical meaning 'to remain'; instead, it contributes the information that the event of seeing someone on the street happened suddenly and unexpectedly.
(4) Bir küni
men uni
kochida körüp qaldim.
Bir kün-i
men u-ni
kocha-da kör-(i)p qal-di-m
one day-3.POSS 1SG 3SG-ACC street-LOC see-LINK remain-PST-1SG

'I saw her/him in the street one day by chance.'

(Tömür 2003, 413)

In both of the above types of -(i)p construction as well as RVCs, -(i)p can be replaced with its negative counterpart, - may. ${ }^{3}$ When $-(i) p$ is replaced by -may in an RVC, the construction effectively ceases to be an RVC, since the two verbs no longer have a causing action-resulting state relationship semantically. Instead, the reading is simply that V2 happened without V1 happening. This is the case when -may instead of -(i)p is suffixed to V1 uru 'to hit' in (5).

(5) Ahmat mitalni urumay tüzliwetti.

Ahmat mital-ni uru-may tüzle-wet-di-0

(name) metal-ACC hit-NEG flatten-COMPL-PST-3

'Ahmat flattened the metal without hitting it.'

We assume that -may can occupy the same functional head as -(i)p, but do not delve into the details of its syntactic identity in this paper.

${ }^{3}$ - may is likely the sentential negation marker - ma, with the vowel changing due to its word-final position. An alternative analysis is that it is $-m a+-(i) p$ having undergone some phonological fusion (Abdurusul 2014). If each instance of -(i) $p$ is replaced by -may in (3), the reading is that the subjects did not eat, drink or chat, but only danced. Alternatively, replacing any single occurrence of -(i) $p$ with -may negates the individual verbal constituent (e.g., only negating 'chat' can mean 'We ate, drank, but didn't chat while dancing') and optionally all preceding verbal constituents (i.e., negating 'chat' can also mean 'We didn't eat, drink or chat while dancing'). If V1 were negated by -may in (4), the reading in the right context would be that the speaker failed to see the object, and this failure to see them was an unexpected change of affairs. 


\section{3. -wet as a completive suffix}

Although either V1 or V2 may describe an action leading to a result state in Uyghur, the suffix -wet is perceived by native speakers as the source of the construction's resultative meaning. This suffix, which is likely a grammaticalized form of the verb ewet 'to send' (Ibrahim 1995; Tömür 2003), attaches to transitive verbs and can indicate that the object enters a state of being 'entirely completed' (Tömür 2003, 418) or is otherwise affected (Tuohuti 2012).

Native speakers find that sentences like (6a) without -wet emphasize a process, while sentences like (6b) with -wet emphasize an outcome.

(6) a. Ahmat mitalni sürtüp parqirtti.

Ahmat mital-ni sürt-(i)p parqir-t-di-0

(name) metal-ACC scrub-LINK shine-CAUS-PST-3

'Ahmat scrubbed and shined the metal.'

b. Ahmat mitalni sürtüp parqirtiwetti.

Ahmat mital-ni sürt-(i)p parqir-t-wet-di-0

(name) metal-ACC scrub-LINK shine-CAUS-COMPL-PST-3

'Ahmat scrubbed the metal shiny.'

RVCs are telic with (7a) or without the -wet suffix (7b). The change of state entailed by V2's meaning is not defeasible in either case, as indicated by the infelicity of the second clause in both (7a) and (7b).

(7) a. Ahmat mitalni sürtüp parqirtiwetti,

Ahmat mital-ni sürt-(i)p parqir-t-wet-di-0

(name) metal-ACC scrub-LINK shine-CAUS-COMPL-PST-3

(" lékin mital parqirmidi).

(" lékin mital parqir-ma-di-0)

but metal shine-NEG-PST-3)

'Ahmat scrubbed the metal shiny, (" but the metal didn't shine).'

b. Ahmat mitalni sürtüp parqirtti,

Ahmat mital-ni sürt-(i)p parqir-t-di-0

(name) metal-ACC scrub-LINK shine-CAUS-PST-3

(" lékin mital parqirmidi).

( ${ }^{\#}$ lékin mital parqir-ma-di-0)

but metal shine-NEG-PST-3)

Intended: 'Ahmat scrubbed the metal shiny, (" but the metal didn't shine).' 
However, the extension of the resulting state is different when -wet is used. (6b) can be felicitously used to describe a situation where the subject polished some portion of a piece of metal shiny (and this portion did become shiny), but not the entire piece of metal. (6a) can only be used when the entire piece of metal has been polished shiny. Thus the meaning contributed by -wet is one of completion, consistent with Tömür's (2003) description. Inclusion of -wet is likely preferred by native speakers because the default reading of a resultative sentence is one in which the entirety of an object undergoes a change of state.

Uyghur linguists also state that -wet as it exists in modern Uyghur grammar attaches to transitive verbs, and it has what some consider an intransitive counterpart: the auxiliary verb ket (Tömür 2003). The lexical entry of ket means 'to leave', but this meaning is sometimes lost when it is immediately preceded by an -(i) $p$-suffixed verb. In this auxiliary context, ket marks an involuntary and complete change of state, as exemplified in $(8)$.

(8) U yiqilip ketti.

U yiqil-(i)p ket-di-0

3SG fall-LINK leave-PST-3

'(S)he fell over (not just partially then got up).'

(Tuohuti 2012, 445)

Indeed, ket is used in place of -wet in RVCs when V2 is unaccusative, as shown in (9). Notice that, like -wet in transitive resultative constructions, ket only appears once, in a sentence-final position save for tense and person inflection.
(9) Derya qattiq muzlap tonglap ketti.
Derya qattiq muzla-(i)p tongla-(i)p ket-di-0
river solid become.ice-LINK freeze-LINK leave-PST-3
'The river froze solid.'

We say that ket is sometimes thought of as an intransitive counterpart to -wet. However, this is not to say that we consider both morphemes to occupy the same head. Sugar (2018) gives arguments for considering ket in this semantically bleached context to be an auxiliary high in the inflectional domain. One of the main reasons is that the auxiliary ket appears higher than passive voice (realized as -il in Uyghur), as shown in (10). 
(10) Dérizining eyniki shamalda chéqilip ketti.

Dérize-ning eynek-i shamal-da chaq-il-(i)p ket-di-0

Window-GEN glass-3.POSS wind-LOC break-PASS-LINK leave-PST-3

'The window was shattered in the wind.'

(Xialipu 2014, 147)

Unlike ket, however, -wet appears lower than passive voice, as demonstrated in (11).

(11) Mital urup tüzliwetildi.

Mital ur-(i)p tüzle-wet-il-di-0

Metal hit-LINK flatten-COMPL-PASS-PST-3

'The metal was hit flat.'

We conclude this section by noting that -wet (and its intransitive counterpart ket) is usually found in RVCs, but is not a defining feature of the construction because of its optionality. It is usually present because the default reading of a resultative is one where an undergoer completely undergoes a change of state, but this is not a requirement of the construction. We therefore abstain from discussion of -wet's (or ket's) position in a syntactic spine, and save the syntactic properties of these morphemes as a topic for further research.

\section{Constraints on verb order}

Recall from section 1 that either V1 or V2 can entail a result state. The verb that does not entail a result state is then interpreted as specifying the manner of bringing about the result state. However, it is not the case that V1 and V2 are free to switch places in any RVC. The generalization that seems to hold is that a verb can be V2 in an RVC only if it and the object form a telic verb constellation (in the sense of Smith 1991).

In the examples in (12), either the verb sürt 'to polish' or parqir-t 'to shine' can be V1 or V2. The English translations given for each example show which verb is interpreted as a manner and which as entailing a result. These translations are really paraphrases, though; both sentences could simply be translated as 'Ahmat scrubbed the metal shiny'.

(12) a. Ahmat mitalni sürtüp parqirtiwetti.

Ahmat mital-ni sürt-(i)p parqir-t-wet-di-0

(name) metal-ACC scrub-LINK shine-CAUS-COMPL-PST-3

'Ahmat shined the metal by scrubbing it.' 
b. Ahmat mitalni parqirtip sürtiwetti.

Ahmat mital-ni parqir-t-(i)p sürt-wet-di-0

(name) metal-ACC shine-CAUS-LINK scrub-COMPL-PST-3

'Ahmat scrubbed the metal while shining it.'

We use the in-adverbial test (Vendler 1957) to show that both verbs in the above sentences form telic verb constellations with the object mital-ni 'the metal'. The time adverbial bir sa'et-da 'in an hour' means that an event culminated within an hour, and its felicity can be used to indicate telicity in Uyghur sentences (Aihemaiti 2013; Sugar 2015). The acceptability of this time adverbial in both (13) and (14) indicate that both verbs sürt and parqir-t are telic in combination with the definite object mital-ni.

(13) Ahmat bir sa'ette mitalni sürtti.

Ahmat bir sa'et-da mital-ni sürt-di-0

(name) one hour-LOC metal-ACC scrub-PST-3

'Ahmat scrubbed the metal in an hour.'

(14) Ahmat bir sa'ette mitalni parqirtti.

Ahmat bir sa'et-da mital-ni parqir-t-di-0

(name) one hour-LOC metal-ACC shine-CAUS-PST-3

'Ahmat shined the metal in an hour.'

(15) shows that the verbs muzla 'to become ice' and tongla 'to freeze' may also be interchanged to form an RVC expressing the same meaning. Both verbs are unaccusative and the RVC formed from their combination is an achievement rather than accomplishment.
Derya qattiq muzlap
tonglap ketti.
Derya qattiq muzla-(i)p
tongla-(i)p ket-di-0
river solid become.ice-LINK freeze-LINK leave-PST-3
'The river froze solid.'

b. Derya qattiq tonglap muzlap ketti.

Derya qattiq tongla-(i)p muzla-(i)p ket-di-0

River solid freeze-LINK become.ice-LINK leave-PST-3

'The river froze solid.'

Applying the in-adverbial test to muzla (16) and tongla (17), we see that both verbs form a telic verb constellation with the internal argument derya 'river'. 
(16) Derya bir sa'ette muzlidi.

Derya bir sa'et-da muzla-di-0

river one hour-LOC become.ice-PST-3

'The river became ice in an hour.'

(17) Derya bir sa'ette tonglidi.

Derya bir sa'et-da tongla-di-0

river one hour-LOC freeze-PST-3

'The river became froze in an hour.'

So far we have seen examples in which V1 and V2 are interchangeable whether they are transitive or unaccusative. In all cases the verbs in question form telic verb constellations with an internal argument.

In (18), however, the only acceptable verb order is where ur 'to hit' is V1 and tüzle 'to flatten' is V2.

(18) a. Ahmat mitalni urup tüzliwetti.

Ahmat mitalni ur-(i)p tüzle-wet-di-0

(name) metal-ACC hit-LINK flatten-COMPL-PST-3

'Ahmat hit the metal flat.'

b. ?Ahmat mitalni tüzlep uruwetti.

Ahmat mitalni tüzle-(i)p ur-wet-di-0

(name) metal-ACC flatten-LINK hit-COMPL-PST-3

Intended: 'Ahmat hit the metal by/while flattening it.'

When we apply the in-adverbial test to these two verbs, we see that tüzle is compatible with the time adverbial bir sa'et-da 'in an hour' (19) but ur is not (20).

(19) Ahmat mitalni bir sa'ette mitalni tüzlidi.

Ahmat mital-ni bir sa'et-da mital-ni tüzle-di-0

(name) metal-ACC one hour-LOC metal-ACC flatten-PST-3

'Ahmat flattened the metal in an hour.'

(20) "'Ahmat mitalni bir sa'ette mitalni urdi.

Ahmat mital-ni bir sa'et-da mital-ni ur-di-0

(name) metal-ACC one hour-LOC metal-ACC hit-PST-3

Intended: 'Ahmat hit the metal in an hour.'

The infelicity of (20) indicates that the verb ur 'to hit' forms an atelic verb constellation with its definite object, and thus ur cannot be the V2 of an RVC. 
The same point can be made using an intransitive verb pair. The order of V1 yighla 'to cry' and V2 höl qil 'to make soggy' is not interchangeable in $(21){ }^{4}$

(21) a. Ahmat qolyaliqni yighlap höl qiliwetti.

Ahmat qolyaliq-ni yighla-(i)p höl qil-wet-di-0

(name) handkerchief-ACC cry-LINK soggy do-COMPL-PST-3

'Ahmat cried the handkerchief soggy.'

b. ?'Ahmat qolyaliqni höl qilip yighlidi.

Ahmat qolyaliq-ni höl qil-(i)p yighla-wet-di-0

(name) handkerchief-ACC soggy do-LINK cry-COMPL-PST-3

Intended: 'Ahmat cried the handkerchief soggy.'

Once again, the in-adverbial test shows us that höl qil is telic (22) while yighla is not (23).

(22) Ahmat bir sa'ette qolyaliqni höl qiliwetti.

Ahmat bir sa'et-da qolyaliq-ni höl qil-wet-di-0

(name) one hour-LOC handkerchief-ACC soggy do-COMPL-PST-3

'Ahmat made the handkerchief soggy in an hour.'

(23) ?'Ahmat bir sa'ette yighlidi.

Ahmat bir sa'et-da yighla-di-0

(name) one hour-LOC cry-PST-3

Intended: 'Ahmat cried in an hour.'

Our conclusion, then, is that V2 must form a telic verb constellation with the object in a felicitous resultative construction. This finding suggests that while Uyghur RVCs differ from those of other languages (known to us) in that the result state may be specified in either V1 or V2, they obey the cross-linguistic generalization that RVCs are telic (Wechsler 2001). ${ }^{5}$

${ }^{4}$ Höl qil 'make soggy', like ussul oyna 'dance play' from (3), is a compound verb, in this case formed by adding the light verb qil 'do' to the adjective höl 'soggy'. It is also worth noting that sentence (21b) can be acceptable on a reading where the wetting of the handkerchief and the crying are two separate events. It is unacceptable if a resultative reading is intended.

${ }^{5}$ As Goldberg and Jackendoff (2004) point out, however, there are many exceptions to the generalization that resultatives are telic, e.g., For hours, Bill heated the mixture hotter and hotter in English (ibid., 543). 


\section{Monoclausality}

A hallmark of RVCs cross-linguistically is that they are monoclausal (Tomioka 2007; Thepkanjana \& Uehara 2009), but diagnostics of monoclausality vary cross-linguistically (Butt 2010). Let us assume that monoclausality means that both tense and voice are shared by all predicates in a construction. Sugar 2017 finds that -(i)p constructions can reliably be split into monoclausal or biclausal types based on whether each (transitive) verb in the construction requires an overt passive marker for the entire sentence to have a passive reading. ${ }^{6}$ (24a) is a standard passive sentence. In (24b), an embedded clause ta yédi '(someone) ate food' is the complement of matrix verb de 'say.' Here only the matrix verb de is passivized. The sentence is grammatically acceptable, but only on the reading that something was said; passivizing the matrix verb de 'say' does not give a passive reading to the embedded verb ye 'eat'.
(24) a. Tamaq yéyildi.
Tamaq ye-il-di-0
b. 'Tamaq yédi déyildi.
Tamaq ye-di-0 de-il-di-0
food eat-PASS-PST-3
'The food was eaten.'
food eat-PST-3 say-PASS-PST-3
'It was said that [somebody] ate food.'

(25) shows a multiclausal lexical -(i) $p$ construction in which two lexical verbs are connected by -(i) $p$. The sentence is only grammatical if the non-

${ }^{6}$ For purposes of exposition, we limit the discussion in this section to just one clausality test involving passivization. The other tests indicating monoclausality from Sugar 2017 include: the ability of a single negative marker on V2 to negate the whole construction, the ability of a negative marker on V1 to license an NCI subject, and the ability of a negative marker on V2 to license a pre-V1 NCI adverbial. The results of all four tests applied to RVCs are shown in the following table (' + ' indicates monoclausality).

\begin{tabular}{lc}
\hline Clausality test & Result \\
\hline Single passive marking & + \\
Single negation & + \\
NCI subject licensing & + \\
NCI adverbial licensing & - \\
\hline
\end{tabular}

The final test is probably not suited to RVCs for semantic reasons. Given that resultatives entail that an internal argument undergoes a complete change of state, it does not make sense to say that an argument did not undergo a change of state 'that much'. Either an argument does or does not change states, but it cannot do so only partway. 
final verb, tüz 'complile', as well as the final verb neshr qil 'publish' are both marked with the passive voice suffix $-i l / i n .^{7}$

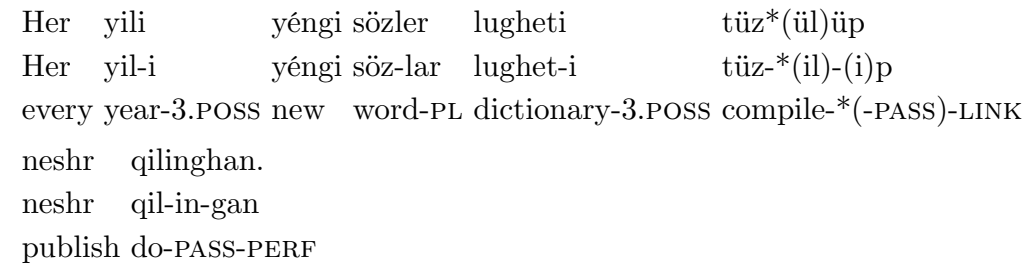

In the monoclausal auxiliary construction (26), on the other hand, the sentence is not acceptable when the non-final verb, renje-t 'to annoy', is suffixed by the passive marker. A passive marker on the aspectual auxiliary qoy alone is sufficient to yield a passive reading of both predicates.

(26) Akingiz

Aka-ingiz

$$
\text { anche renjit }(* \text { il)ip qoyulmidi. }
$$

older.brother-2SG.FORM.POSS so.much annoy-(*-PASS)-(i)p put-PASS-NEG-PST-3SG

'Your older brother wasn't annoyed that much.'

Uyghur RVCs pattern with the aspectual auxiliary construction in (26) in that only the final verb needs be passivized for the whole sentence to have a passive reading. (27), the passivized version of (1), is acceptable only when the passive suffix - $i l$ appears on the final verb alone.

(27) Mital ur(*ul)up tüzliwetildi.

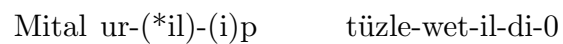

metal hit-(*-PASS)-LINK flatten-COMPL-PASS-PST-3

'The metal was hit flat.'

We have seen, then, that RVCs display monoclausal behavior in that passivizing one verb passivizes the entire construction. Here we can understand monoclausality as the presence of only one voice head which affects both verbs. Given that both verbs are located under the same voice head, a crucial question is whether one verb is the complement of the other, or one verb is adjoined to the other. The following sections discuss the structural relationship between the two verbal constituents that form an RVC.

${ }^{7}$ In Uyghur, the possessive marker - $i$ often appears on modified nouns, as is the case with lughet 'dictionary' in (25). This possessive marking happens separately from case marking. (Nominative case is not overtly realized in Uyghur.) 


\section{Resultative constructions are formed by adjunction}

This section argues that Uyghur RVCs are formed by adjoining a secondary predication to a primary predication. This differs from RVCs in English and Chinese, in which the secondary predication has been analyzed as a complement of the primary predication.

Typical English RVCs are realized by a verb followed by a non-verbal element that acts as a secondary predication. The secondary element is always the last element in the construction, and it describes a state reached by an undergoer argument as a result of the verb's event. In (28), for example, the adjective green is the state attained by the door as a result of the subject's painting it.

(28) He painted the door green.

(Halliday 1967, cited in Tomioka 2007, 1)

In Mandarin Chinese, a secondary predicate immediately follows the main verb, appearing before the syntactic object in transitive constructions. In (29), the verbal adjective lèi 'tired' immediately follows the verb zhū 'to chase', and can be predicated either of the sentence's subject or object.

(29) Baoyu zhū̄ lèi le Daiyu.

(name) chase tired AsP (name)

'Bayou chased Daiyu and as a result Daiyu/Baoyu got tired.'

(Zhang 2007, 54)

Resultatives in these languages have been analyzed as the second predicate being a complement of the first predicate. One reason for such an analysis is that neither the first nor second verb can be iterated, suggesting that there is no adjunction in the constructions (Rothstein 1983). (30) shows that the V2 of English example (28) may not be iterated, and (31) shows the same for Chinese example (29).

(30) *John painted the door green red.

(31) *Baoyu zhū lèi fán le Daiyu.

(name) chase tired annoyed ASP (name)

Intended: 'Bayou chased Daiyu and as a result Daiyu/Baoyu got tired and annoyed.'

In this section, we will show that unlike English or Chinese, Uyghur RVCs involve adjunction rather than complementation. In addition to showing that V1 is capable of iterating, we also demonstrate that V2 is selectionally dominant over $\mathrm{V} 1$ in terms of argument structure, situation aspect type, and object case marking. 


\subsection{Iterations of V1}

In any language, adjuncts can be iterated indefinitely without a coordination marker (e.g., I walked to the store with a friend to buy some milk at 4pm while whistling). Complements, however, are in a one-to-one relationship with a syntactic head, and thus cannot be multiply iterated without coordination (e.g., ${ }^{*}$ I ate noodles chicken).

Shibagaki (2011) considers Mongolian RVCs to involve adjunction because multiple non-final predicates can appear in one RVC. Non-final predicates in Mongolian are suffixed by the -tal marker in a similar fashion to -(i) $p$ in Uyghur. In (32), two -tal-marked phrases precede the final verb davt 'hammer', and both are interpreted as expressing resulting states of the hammering action.

(32) John ene metal-ig [helber n' havtgai bol-to] [öngö n'

John this metal-ACC shape 3.POss flat become-CVB colour 3.POSS

aril-tal] davt-san.

delete-CvB hammer-PST

'John hammered the metal; as a result its shape became flat and it lost its color.'

(ibid., 169)

In Uyghur, an additional -(i)p-suffixed verb can be added to any RVC, as long as the additional verb denotes an event that can semantically be understood as a manner of carrying out the event denoted by V2, or conversely, if all non-final verbs entail result states brought about by the manner of action described by V2. (33) and (34) are two RVCs in which qizil qil 'to make red' and kök qil 'to make blue' respectively modify the final verb boy 'to paint', and (35) is an acceptable sentence in which both verbs take the $-(i) p$ suffix and modify the final verb.

(33) Ahmat tamni qizil qilip boyiwetti

Ahmat tam-ni qizil qil-(i)p boy-wet-di-0

(name) wall-ACC red do-LINK paint-COMPL-PST-3

'Ahmat painted the wall red.'

(34) Ahmat tamni kök qilip boyiwetti

Ahmat tam-ni kök qil-(i)p boy-wet-di-0

(name) wall-ACC blue do-LINK paint-COMPL-PST-3

'Ahmat painted the wall blue.' 
(35) Ahmat tamni qizil qilip kök qilip boyiwetti

Ahmat tam-ni qizil qil-(i)p kök qil-(i)p boy-wet-di-0

(name) wall-ACC red do-LINK blue do-LINK paint-COMPL-PST-3

'Ahmat painted the wall red and blue.'

Intransitive V1s can also iterate, as shown in (36), an expansion of $(37 \mathrm{c}) .^{8}$

(36) Ahmat qolyaliqni yighlap chüshkürüp höl qiliwetti.

Ahmat qolyaliq-ni yighla-(i)p chüshkür-(i)p höl qil-wet-di-0

(name) handkerchief-ACC cry-LINK sneeze-LINK soggy make-COMPL-PST-3

'Ahmat cried and sneezed his handkerchief soggy.'

The fact that V1 does not stand in a one-to-one relationship with V2 means that the former must not be a complement of the latter. In the following subsections we show that not only is V1 iterable; it has no part in determining the argument structure, aspectual type or case marking of the construction.

\subsection{Transitivity}

In Uyghur RVCs, it is always V2, not V1, that determines the argument structure of the whole construction. The impossibility of an accusative

${ }^{8}$ An anonymous reviewer asks whether (35) and (36) might be cases of coordination such that the two V1s are treated as a single constituent, and not in fact iterated. One reason to think the $-(i) p$ structure of these examples is not a coordination structure is the fact that coordination is at least marginally possible with the addition of the overt conjunction we 'and' in (i).

(i) 'Ahmat tamni qizil qilip we kök qilip boyiwetti

Ahmat tam-ni qizil qil-(i)p we kök qil-(i)p boy-wet-di-0

(name) wall-ACC red do-LINK and blue do-LINK paint-COMPL-PST-3

'Ahmat painted the wall red and blue.'

We is used productively to coordinate many types of constituents in Uyghur, including verb phrases of matching finiteness. However, we know of no cases elsewhere in Uyghur grammar where two constituents may be coordinated without an overt coordination marker like we, except between two non-final coordinands in a string of three or more.

Additionally, recent generative syntactic work has argued for empirical and theoretical reasons that coordination is asymmetric and in fact a form of adjunction (Munn 1993; Cormack \& Smith 2005; Weisser 2015). Thus, we do not consider the possibility that multiple V1s are coordinated to be problematic for our overall argument that the relationship between V1 and V2 is one of adjunction, although the issue warrants further investigation. 
object in (37a) shows that the verb yighla 'to cry' is intransitive. By contrast, the need for an accusative object in (37b) shows that the verb höl qil 'to make soggy' is transitive. When the two verbs are combined in an RVC (37c), the result is a transitive construction with two arguments, and the accusative object appears before both verbs.
a. Ahmat (*qolyaliqni) yighlidi.
Ahmat (*qolyaliq-ni) yighla-di-0
(name) handkerchief-ACC cry-PST-3
'Ahmat cried (*the handkerchief).'
b. Ahmat (*qolyaliqni) höl qilwetti.
Ahmat (*qolyaliq-ni) höl qil-wet-di-0
(name) handkerchief-ACC soggy make-PST-3
'Ahmat made his handkerchief soggy.'
c. Ahmat (*qolyaliqni) yighlap höl qilwetti.
Ahmat (*qolyaliq-ni) yighla-(i)p höl qil-wet-di-0
(name) handkerchief-ACC cry-LINK soggy make-COMPL-PST-3
'Ahmat cried his handkerchief soggy.'

Since V1 is not selectionally dominant, we argue that it is an adjunct modifying V2.

\subsection{Aspect of the RVC is determined by V2, not V1}

In addition to determining the argument structure of the construction, V2 also determines the RVC's situation aspect type. This should come as no surprise, since section 4 established that only V2 of an Uyghur RVC need be telic, and telicity is a cross-linguistically typical characteristic of RVCs (Tomioka 2007; Shibagaki 2011).

Repeating the examples from section 4, the examples in (38) show the in-adverbial tests applied to the verbs ur 'to hit' (38a) and tüzle 'to flatten' (38b), and then in (38c) to the RVC combining both verbs that was first given in (1).

(38) a. 'Ahmat bir sa'ette mitalni uruwetti.

Ahmat bir sa'et-da mitalni ur-wet-di-0

(name) one hour-LOC metal-ACC hit-COMPL-PST-3

Intended: 'Ahmat hit the metal in an hour.' 
b. Ahmat bir sa'ette mitalni tüzliwetti.

Ahmat bir sa'et-da mitalni tüzle-wet-di-0

(name) one hour-LOC metal-ACC flatten-COMPL-PST-3

'Ahmat flattened the metal in an hour.'

c. Ahmat bir sa'ette mitalni urup tüzliwetti.

Ahmat bir sa'et-da mitalni ur-(i)p tüzle-wet-di-0

(name) one hour-LOC metal-ACC hit-LINK flatten-COMPL-PST-3

'Ahmat hit the metal flat in an hour.'

The in-adverbial test shows that only V2 must share the aspectual feature of telicity with the entire construction. V1 appears not to take part in the construction's aspectual composition.

\subsection{Object case is selected by V2, not V1}

Following a similar trend to the previous two subsections, the case of sentential objects in RVCs is determined by V2, not V1.

The verb teg 'to touch' selects dative rather than accusative objects, as shown in (39).

(39) Adil telewizorge $/ *^{*}$ i tegdi.

Adil telewizor-ga $/{ }^{*}$ ni teg-di-0

(name) television-DAT $/{ }^{*} \mathrm{ACC}$ touch-PST-3

'Adil touched the television.'

The verb buz 'to break', however, selects accusative rather than dative objects, as shown in (40).

(40) Adil telewizor*ge/ni buziwetti.

Adil telewizor- ${ }^{*}$ ge/ni buz-wet-di-0

(name) television-*DAT/ACC break-COMPL-PST-3

'Adil broke the television.'

When the two verbs are combined in an RVC like (41), the object must be accusative, which is required by V2 buz, and contrary to the requirement of V1 teg.

(41) Adil telewizor*ge/ni tégip buziwetti.

Adil telewizor- $*_{g a} /$ ni teg-(i)p buz-wet-di-0

(name) television-*DAT/ACC touch-LINK break-COMPL-PST-3

'Adil broke the television by touching it.' 
We have seen in this section that V2, and not V1, determines the transitivity, situation aspect type, and object case of the RVC, and that V1 is iterable. Together, these facts provide evidence that the non-final verbs are adjoined to rather than complements of the final verb in Uyghur. Having established that the relationship between the two verbs is one of adjunction, we turn to possible site of adjunction in the next section.

\section{Location: inside $v P$}

So far, we have established that V1 of an Uyghur RVC adjoins to V2. In this section we suggest that the site of adjunction is within the second verb phrase. To do so, we first establish that V2 is structurally superior to V1, then show that both verbs appear at a low structural position in the clause, and finally use pseudocleft and 'do so' tests to show that V1 appears within V2.

\subsection{V2 Is Structurally Superior to V1}

One reason to believe that V2 is structurally superior to V1 has to do with the scope of negation. Negative markers should be able to semantically negate any predicate that they c-command (see Zeijlstra 2004; Collins \& Postal 2014 and references therein). While either verb may be negated, only negating V2 can semantically negate both verbs. (42), in which V2 boy 'to paint' is negated by the - $m a$ suffix, means that the subject neither painted the wall nor made it red.

(42) Biz tamni qizil qilip boyiwetmiduq.

Biz tam-ni qizil qil-(i)p boy-wet-ma-di-uq

1PL wall-ACC red do-LINK paint-COMPL-NEG-PST-1PL

'We didn't paint the wall red.'

V1 qizil qil 'to redden' is negated in (43). The reading is that subject painted the wall, but did not make it red.

(43) Biz tamni qizil qilmay boyiwettuq.

Biz tam-ni qizil qil-may boy-wet-di-uq

1PL wall-ACC red do-NEG paint-COMPL-PST-1PL

'We painted the wall without making it red.'

By a similar token, the scope of passivization shows that V2 is superior to V1. Recall from section 5 that only one verb, V2, in an RVC may take the 
passive suffix $-i l / i n$, and it results in a passive reading of the entire clause. V1 cannot be passivized. (27), repeated here as (44), gives an example in which V2 tüzle 'to flatten', but not V1 ur 'to hit' may take a passive suffix.

(44) Mital ur $\left({ }^{*} u l\right)$ up tüzliwetildi.

Mital ur- $(*$ il)-(i)p tüzle-wet-il-di-0

Metal hit-(*-PASS)-LINK flatten-COMPL-PASS-PST-3

'The metal was hit flat.'

We take the inability of $\mathrm{V} 1$ to passivize as an indication that V2 is in closer proximity to the voice head.

We have shown here that V2 is in a structurally superior position to V1 since negating V2 negates V1 and passivizing V2 passivizes V1. Having established V2's structural superiority, we show both verbs' low clausal position in the following subsection.

\subsection{Below celerative adverbials}

This section shows that both V1 and V2 occur lower in the clausal spine than celerative adverbials. In his elaborate mapping of functional projections, Cinque (1999) shows that celerative adverbials occupy one of the lowest positions of any type of adverbial, close to Voice or $v$. This seems to be the case in Uyghur. Celerative adverbials must appear in a higher position than the base-merged position of indefinite objects, which are not overtly case marked (45a). However, definite objects with overt accusative case move to a functional projection between $\mathrm{T}$ and $v$, and this position is higher than that of celerative adverbials (45b).

(45) a. Ahmat asta asta mital (*asta asta) urdi.

Ahmat asta asta mital (*asta asta) ur-di-0

(name) slow slow metal slow slow hit-PST-3

'Ahmat slowly hit metal.'

b. Ahmat (*asta asta) mitalni asta asta urdi.

Ahmat (*asta asta) mital-ni asta asta ur-di-0

(name) slow slow metal-ACC slow slow hit-PST-3

'Ahmat hit the metal slowly.'

The examples in (46) demonstrate that both verbs in an RVC can only appear below, not above, celerative adverbials. In the grammatical example (46a), both V1 ur 'to hit' and V2 tüzle 'to flatten' follow the celerative 
adverbial asta asta 'slowly'. In (46b), however, asta asta follows ur, and the result is ungrammatical.

(46) a. Ahmat mitalni asta asta urup tüzliwetti.

Ahmat mital-ni asta asta ur-(i)p tüzle-wet-di-0

(name) metal-ACC slow slow hit-LINK flatten-COMPL-PST-3

'Ahmat slowly hit the metal flat.'

b. ${ }^{*}$ Ahmat mitalni urup asta asta tüzliwetti.

Ahmat mital-ni ur-(i)p asta asta tüzle-wet-di-0

(name) metal-ACC hit-LINK slow slow flatten-COMPL-PST-3

Intended: 'Ahmat slowly hit the metal flat.'

This test shows that the site of adjunction of V1 is low in the clause, no higher than $v \mathrm{P}$.

\subsection{V1 not separable from V2}

The pseudo-cleft test has been used to determine whether resultative predicates are within a single $v \mathrm{P}$ since Roberts 1988. (47b) shows a standard English pseudocleft sentence based on the English RVC (47a). In (47c), the resultative predicate flat is pseudoclefted outside the $v \mathrm{P}$, resulting in ungrammaticality.

(47) a. John hammered the metal flat.

b. What John did was [hammer the metal flat].

c. *John did flat was [hammer the metal].

Much like English, pseudoclefting of Uyghur resultatives reveals that both verbs are part of the same $v \mathrm{P}$. (48a) shows the standard format for an Uyghur pseudocleft, with the postposition bolsa 'as for' marking the pseudoclefted constituent as a topic. When V1 is pseudoclefted in (48b), the sentence becomes ungrammatical. When V2 is pseudoclefted in (48c), the sentence becomes similarly ungrammatical.

(48) a. Ahmatning qilghini bolsa mitalni urup tüzliwitish.

Ahmat-ning qil-gan-i bolsa mital-ni ur-(i)p tüzle-wet-ish

(name)-GEN do-PERF-3.POSS TOP metal-ACC hit-LINK flatten-COMPL-INF

'What Ahmat did was hit the metal flat.' 

b. *Ahmatning urup qilghini bolsa mitalni tüzliwitish Ahmat-ning ur-(i)p qil-gan-i bolsa mital-ni tüzle-wet-ish (name)-GEN hit-LINK do-PERF-3.POSS TOP metal-ACC flatten-COMPL-INF Intended: 'What Ahmat did by hitting was flatten the metal.'
c. *Ahmatning mitalni qandaq tüzliwetkini bolsa urush. Ahmat-ning mital-ni qandaq tüzle-wet-gan-i bolsa ur-ish (name)-GEN metal-ACC how flatten-COMPL-PERF-3.POSS TOP hit-INF Intended: 'How Ahmat flattened the metal was by hitting it.'

'Do so' ellipsis tests yield a similar result. Eliding a verbal constituent and replacing it with do (so) too is known to target an entire verb phrase (Déchaine 1993 and references therein). Material that can be stranded outside the site of ellision, like the English temporal adjuncts in the winter/in the spring in (49), must be outside the verb phrase. Material that cannot be stranded, like the English object-oriented adjuncts in tatters/in a mess in (50), must be inside the verb phrase.

(49) John visited Rome in the spring, and Sal did so in the winter.

(50) *Joan submitted her book in a mess, and Sal did so in tatters.

(ibid., 201, citing Lakoff \& Ross 1966)

The 'do so' ellipsis test can be used in Uyghur by replacing a verbal constituent with shundaq qil 'do so'. (52) shows three sentences intended to follow the statement in (51). In (52a), the predicate of (51) is elided and replaced with shundaq qildi 'did so'. This is a grammatical utterance because the entire verb phrase is elided. In (52b), the time adverbial tünügün 'yesterday' from (51) is replaced with bügün 'today', while the predicate is elided. This is also grammatical, because the time adverbials occur outside the verb phrase. However, (52c) is ungrammatical because V1 bas 'to press' is not elided with the rest of the verb phrase.

(51) Ahmat tünügün mitlani urup tüzliwetti.

Ahmat tünügün mital-ni ur-(i)p tüzle-wet-di-0.

(name) yesterday metal-ACC hit-LINK flatten-COMPL-PST-3

'Ahmat hammered the metal flat yesterday.' 
(52) a. Ablizmu shundaq qildi.

Abliz-mu shundaq qil-di-0

(name)-also like.that do-PST-3

'... Abliz also did so.'

b. Ablizmu bügün shundaq qildi.

Abliz-mu bügün shundaq qil-di-0

(name)-also today like.that do-PST-3

'Abliz also did so today.'

c. *Ablizmu bésip shundaq qildi.

Abliz-mu bas-(i)p shundaq qil-di-0

(name)-also press-LINK like.that do-PST-3

Intended: '... Abliz also did so by pressing.'

The fact that V1 can neither be separated from the rest of the predicate in pseudoclefting nor stranded in 'do so' ellipsis shows that both verbal constituents are part of the same verb phrase. Since we have established that V1 is adjoined to V2, this amounts to saying that the adjunction site is within the verbal domain of $v \mathrm{P}$, rather than a higher position in the clause.

\subsection{Resultative structure}

The structure we have been building towards is shown at the tense phrase (TP) level with only subject and object movement in (53). This structure is monoclausal because there is a single $\mathrm{T}$ head as well as a single $v$ head, which forces both verbs to share the same voice. Both verbs are also in the c-command of the same sentential negation head. The verbs share an object via control, and $\mathrm{V} 1 \mathrm{P}$ adjoins to $v \mathrm{P}$ by way of $-(i) p$. The object is merged in spec, V2P, but raises to a higher CaseP to be marked with overt accusative case (Major \& Yakup 2015). The -(i)p morpheme has traditionally been treated as an adverbial head whose complement is the verb phrase to which it attaches (Tömür 2003; Tuohuti 2012; Abdurusul 2014). -(i)p here heads a functional projection FP whose identity is not yet fully understood. ${ }^{9}$ The $\mathrm{FP}$ adjoins to $v \mathrm{P}$ after $v \mathrm{P}$ 's specifier, the agentive subject, has been merged. Celerative adverbials of the type shown in section 7.2 may adjoin to $v \mathrm{P}$ above the $\mathrm{FP}$.

\footnotetext{
${ }^{9}$ For ideas about -(i)p's identity, see Sugar 2017 and Sugar 2018.
} 
$(53)$

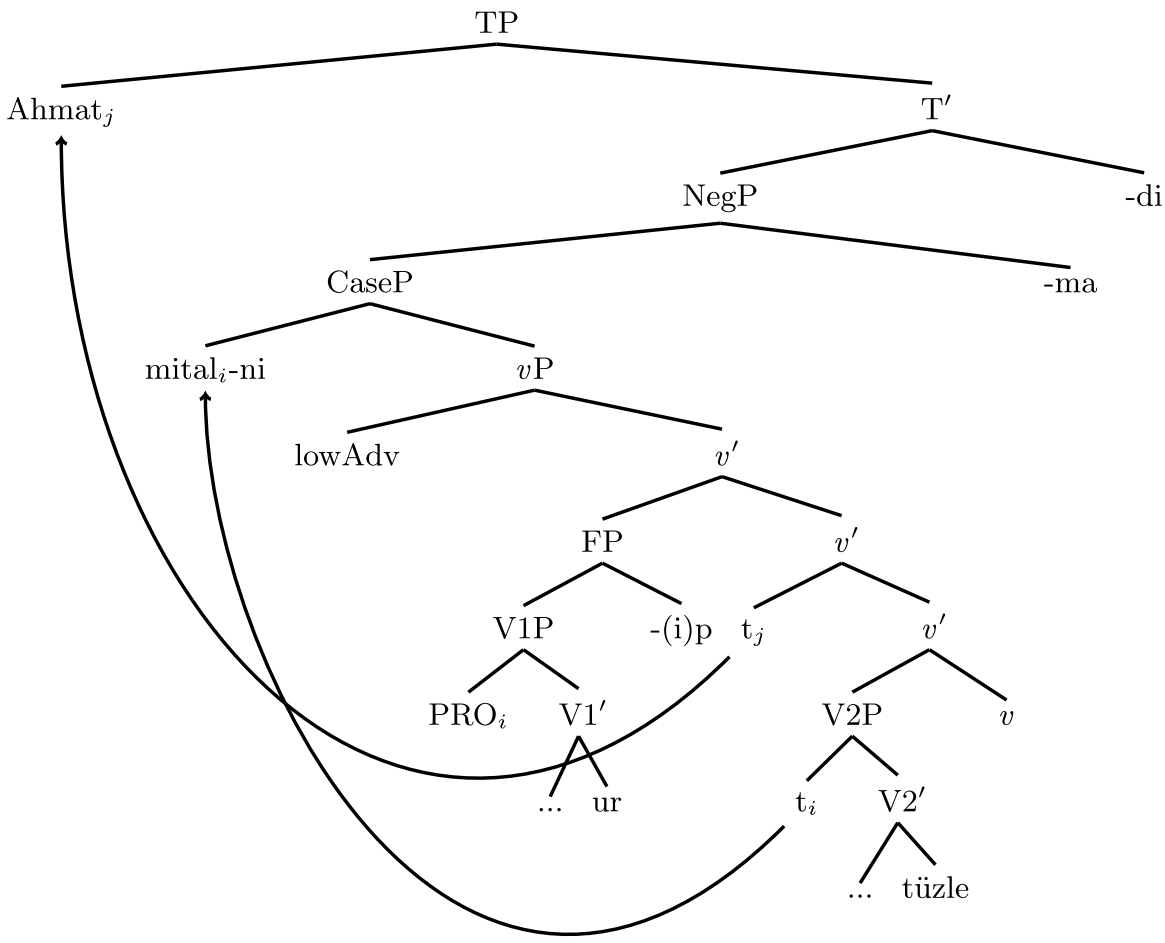

\section{Comparisons to typologically similar languages}

This paper has argued that Uyghur RVCs are formed by the adjunction of V1P to V2P. - ni resultatives by Japanese, another Altaic language by hypothesis, are said not to involve adjunction, since - $n i$-marked V1s cannot iterate, as shown in (54).

(54) Taroo-ga kutu-o pikapika-ni turuturu-ni migai-ta

Taroo-NOM shoe-ACC shine-ni slippery-ni polish-PST

Intended: 'Taro polished the shoes shiny and slippery.'

(Shibagaki 2011, 61)

-key resultatives in Korean, however, have been analyzed as having adjunction, since -key-marked V1s can iterate as in Uyghur.

(55) Jim-i patak-ul (phyomyen-i) hayah-key panccaki-key chilha-ess-ta.

Jim-NOM floor-ACC surface-NOM white-KEY shiny-KEY paint-PST-DC

'Jim painted the floor so that its surface became white (and) shiny.' (ibid., 222) 
Mongolian - tal resultatives have also been analyzed as involving adjunction for the same reason.

(56) John ene metal-ig helber n' havtgai bol-tol öngö n'

John this metal-ACC shape 3.POss flat become-CVB color 3.POSS

aril-tal davt-san.

delete-CVB hammer-PST

'John hammered the metal so that its shape became flat and it lost its color.'

(ibid., 169)

A key difference between RVCs in the three above languages and Uyghur is that in all the examples we have seen from other languages in this section, the result state is always described by V1. However, either V1 or V2 can describe the result state in Uyghur, as we explained in sections 1 and 4. Additionally, the V1s in the above examples are all unaccusatives predicated of the sentential object. For example, metal is the subject of V1 havtgai bol 'to become flat', but the object of V2 davt 'to hammer' in (56). In other words, havtgai bol is an unaccusative verb that does not share a subject with davt. In Uyghur, however, V1 and V2 must share a subject. In (1), repeated here as (57), V1 ur 'to hit' is a transitive verb, and Ahmat is the subject of both ur and V2 tüzle 'to flatten'.

(57) Ahmat mitalni urup tüzliwetti

Ahmat mital-ni ur-(i)p tüzle-wet-di-0

(name) metal-ACC hit-LINK flatten-COMPL-PST-3

'Ahmat hit the metal flat.'

An additional difference between Korean and Uyghur has to do with RVCs formed from unaccusative verbs. Lee (2004) argues that there is a restriction on RVCs in which both verbs are unaccusative, as shown in (58).

(58) *Tungsankayk-tul-i cwuk-key el-ess-ta.

climber-POL-NOM die-KEY freeze-PST-DECL

'The climbers froze to death.'

(Lee 2004, 121)

Lee (2004) attributes the ungrammaticality of (58) to the fact that V1 cwuk 'die' is a telic verb, claiming this is a violation of Tenny's (1994) Single Delimiting Constraint, because both the delimiting states of being dead or being frozen are predicated of the single argument tungsankayk 'climber'.

Uyghur does not obey the Single Delimiting Constraint. In example (15a), repeated here as (59), the non-agentive subject derya 'river' appears 
to be the internal argument of two events with lexically entailed delimiting states (as described in section 4): muzla 'to become ice' and tongla 'to freeze'.
Derya qattiq muzlap
tonglap ketti.
Derya qattiq muzla-(i)p
tongla-(i)p ket-di-0
river solid become.ice-LINK freeze-LINK leave-PST-3
'The river froze solid.'

Why such differences exist in the strategies for expressing resultative relationships between predicates in these languages is a topic for future research.

\section{Conclusion}

This paper has introduced the general properties and structure of Uyghur resultative constructions. They consist of two verbs connected in a monoclausal structure by the -(i)p suffix, which allows V1 to adjoin to structurally superior $\mathrm{V} 2$ at the $v \mathrm{P}$ level. Either V1 or V2 may encode a result state-entailing meaning, while the other verb specifies a manner of action. In all cases, V2 must form a telic skeleton in combination with its internal argument.

The form of Uyghur RVCs differs significantly from those of other hypothesized Altaic languages, not to mention RVCs in other language families. The fact that a resultative relationship between two predicates is expressed by such different means across different languages suggests that the resultative construction is not a universal structure or syntactic primitive. Instead, the semantic interpretation of resultativity may be a common concept achievable by a variety of syntactic forms, as suggested by Goldberg and Jackendoff (2004) and Lee's (2013) arguments for family resemblance between constructions.

Future areas of research include the exact nature of the projection headed by -(i)p and the reasons why Uyghur RVCs do not show some of the same restrictions regarding predicate type that related languages show.

\section{Acknowledgements}

This research was supported by research grant \#2016BS015 from the Xinjiang University of Economics and Trade. We wish to thank Edith Aldridge, Karen Zagona, the University of Washington Syntax and Semantics Roundtables, and two anonymous reviewers for constructive comments and insightful suggestions. All errors are our own. 


\section{References}

Abdurusul, Muzappar. 2014. Weiwueryu de jingcihua duanyu [Deverbalized phrases in Uyghur]. Beijing: Minzu Press.

Aihemaiti, Kayisa'er. 2013. Xiandai weiwu'eryu qingzhuang leixing yanjiu [Situation types in Modern Uyghur]. Urumchi, Xinjiang: Xinjiang People's Press.

Aikhenvald, Alexandra Y. and Robert M. W. Dixon. 2014. The grammar of knowledge: A cross-linguistic typology. Oxford: Oxford University Press.

Butt, Miriam. 2010. The light verb jungle: Still hacking away. In M. Amberber, B. Baker and M. Harvey (eds.) Complex predicates: Cross-linguistic perspectives on event structure. Cambridge: Cambridge University Press. 48-78.

Cinque, Guglielmo. 1999. Adverbs and functional heads: A cross-linguistic perspective. Oxford: Oxford University Press.

Collins, Chris. 1997. Argument sharing in serial verb constructions. Linguistic Inquiry 28. 461-497.

Collins, Chris and Paul M. Postal. 2014. Classical NEG raising: An essay on the syntax of negation. Cambridge, MA: MIT Press.

Cormack, Annabel and Neil Smith. 1994. Serial verbs. UCL Working papers in Linguistics 6. $63-88$.

Cormack, Annabel and Neil Smith. 1999. Why are depictives different from resultatives. UCL Working Papers in Linguistics 11. 251-284.

Cormack, Annabel and Neil Smith. 2005. What is coordination? Lingua 115. 395-418.

Dawut, Ömer. 2011. Uyghur tili medeniyiti tetqiqati [Research on Uyghur language and culture]. Urumchi, Xinjiang: Xinjiang University Press.

Déchaine, Rose-Marie Anne. 1993. Predicates across categories: Towards a category-neutral syntax. Doctoral dissertation. University of Massachusetts Amherst.

Engesæth, Tarjei, Mahire Yakup and Arienne M. Dwyer. 2009. Greetings from the Teklimakan: A handbook of Modern Uyghur. Lawrence, KS: Kansas Scholarworks.

Goldberg, Adele E. and Ray Jackendoff. 2004. The English resultative as a family of constructions. Language 80. 532-568.

Halliday, Michael Alexander Kirkwood. 1967. Notes on transitivity and theme in English (part 2). Journal of Linguistics 3. 199-244.

Ibrahim, Ablahat. 1995. Meaning and usage of compound verbs in Modern Uighur and Uzbek. Doctoral dissertation. University of Washington.

Larson, Richard. 1991. Some issues in verb serialization. In C. Lefebvre (ed.) Serial verbs: Grammatical, comparative and cognitive approaches. Amsterdam \& Philadelphia: John Benjamins. 185-210.

Lee, Leslie. 2013. Event structure and grammatical patterns: Resultative constructions. Doctoral dissertation. University of California, San Diego.

Lee, Mijung. 2004. Resultative constructions in Korean. Doctoral dissertation. University of Hawaii at Manoa.

Major, Travis and Mahire Yakup. 2015. Uyghur A-not-A constructions: Ellipsis after all. Paper presented at the 89th Annual Meeting of the Linguistic Society of America.

Memtimin, Aminem. 2016. Language contact in Modern Uyghur. Wiesbaden: Otto Harrassowitz. 
Munn, Alan. 1993. Topics in the syntax and semantics of coordinate structures. Doctoral dissertation. University of Maryland.

Roberts, Ian. 1988. Predicative aps. Linguistic Inquiry 19. 703-710.

Rothstein, Susan. 2006. Secondary predication. In M. Everaert and H. van Riemsdijk (eds.) The Blackwell companion to syntax. Malden, MA \& Oxford: Blackwell. 209-233.

Rothstein, Susan Deborah. 1983. The syntactic forms of predication. Doctoral dissertation. MIT.

Shibagaki, Ryosuke. 2011. Secondary predication in Chinese, Japanese, Mongolian and Korean. Doctoral dissertation. School of Oriental and African Studies, University of London.

Smith, Carlota S. 1991. The parameter of aspect. Dordrecht: Kluwer.

Sugar, Alexander. 2015. Situation aspect in Uyghur light verbs. Generals paper.

Sugar, Alexander. 2017. Uyghur -ip as a verb linker in multiple constructions. Proceedings of the Linguistic Society of America 2. 1-14.

Sugar, Alexander. 2018. Event and aspect as syntactic heads: Evidence from Uyghur -ip constructions. Poster presented at the 92nd Annual Meeting of the Linguistic Society of America.

Tenny, Carol L. 1994. Aspectual roles and the syntax-semantics interface. (Studies in Linguistics and Philosophy 52). Dordrecht: Kluwer.

Thepkanjana, Kingkarn and Satoshi Uehara. 2009. Resultative constructions with "impliedresult" and "entailed-result" verbs in Thai and English: A contrastive study. Linguistics 47. 589-618.

Tomioka, Naoko. 2007. Resultative constructions: Cross-linguistic variation and the syntax-semantics interface. Doctoral dissertation. McGill University.

Tömür, Khāmit. 2003. Modern Uyghur grammar: Morphology, vol. 3. Istanbul: Yıldız.

Tuohuti, Litipu. 2012. Xiandai weiwueryu cankao yufa [A reference grammar of Modern Uyghur]. Beijing: China Social Sciences Press.

Vendler, Zeno. 1957. Verbs and times. Philosophical Review 66. 143-160.

Wechsler, Stephen. 2001. An analysis of English resultatives under the event-argument homomorphism model of telicity. In Proceedings of the 3rd Workshop on Text Structure. Austin: University of Texas Linguistics Department. 13-15.

Weisser, Philipp. 2015. Derived coordination: A minimalist perspective on clause chains, converbs and asymmetric coordination, vol. 561. Berlin \& New York: Walter de Gruyter.

Xialipu, Aziguli. 2014. Miánxiáng wéhàn jīqì fānyì de dòngcí yánjiū [Research on UyghurChinese machine translation of verbs]. Urumchi, Xinjiang: Xinjiang University Press.

Zeijlstra, Hedde. 2004. Sentential negation and negative concord. Doctoral dissertation. LOT, Utrecht.

Zhang, Niina Ning. 2007. A syntactic account of the direct object restriction in Chinese. Language Research 43. 53-75. 